\title{
PERKEMBANGAN MORFOLOGI DAN PERILAKU LARVA IKAN KERAPU HIBRIDA CANTIK PADA PRODUKSI MASSAL
}

\author{
MORPHOLOGICAL DEVELOPMENT AND BEHAVIOR \\ OF HYBRID GROUPER “CANTIK” LARVAE IN MASS PRODUCTION
}

\author{
Suko Ismi*, Jhon H. Hutapea, Daniar Kusumawati, dan Yasmina Nirmala Asih \\ Balai Besar Riset Budidaya Laut dan Penyuluhan Perikanan Gondol-Bali \\ *E-mail: sukoismi@yahoo.com
}

\begin{abstract}
The "cantik" grouper is produced from hybridization between female tiger "macan" grouper Epinephelus fuscoguttatus and male camoflage "batik" grouper Epinephelus microdo. The purpose of this research to observe the morphological development and behavior of cantik grouper larvae in order to improve its larval rearing management as to increase the production. The research was conducted at the Institute for Mariculture Research and Fisheries Extension, Gondol-Bali in 2016. The experiment was held in three concrete tanks with volume of $10 \mathrm{~m}^{3}$ and grouper eggs were stocked at density of 50,000 eggs / tank, larval were reared until juvenile of 40 days old (D40). Larval rearing were repeated three different times, cycle 1: January-March; cycle 2: May-July and cycle 3: September-November. Observations on morphological development and feeding behavior of cantik grouper larvae were performed on four (4) age groups: 1) D1 to D10; 2). D11 to D20; 3). D21 to D30; and D31 to D40. The results showed that cantik grouper larvae began to open their mouth and start initial feeding at D3, then began to actively swimming after has a dorsal and pectoral fins from D4, the fins continues to grow and first dorsal and ventral fin spine elongated, and at the same time, the larvae tend to cluster on D7, if larvae cluster is too dense thinning is needed. Elongated first dorsal and ventral fin spine is began to shortened from D30 furthermore metamorphose to juvenile and grading should be done in order to suppress cannibalism. At D40 with total length about $3 \mathrm{~cm}$, all the cantik grouper larvae were metamorphosed to juvenile. The growth and behavior of cantik grouper larvae effect their production.
\end{abstract}

Keywords: behavior, development, cantik grouper, observation, support, production

\begin{abstract}
ABSTRAK
Ikan kerapu cantik merupakan hibrida antara betina kerapu macan E. fuscoguttatus dan jantan kerapu batik E. microdon. Penelitian ini bertujuan untuk mengamati perkembangan dan tingkah laku larva ikan kerapu cantik agar bisa diambil langkah-langkah untuk perbaikan pada pemeliharaan larva sehingga dapat meningkatkan produksi. Penelitian dilakukan di Balai Besar Riset Budidaya Laut dan Penyuluhan Perikanan Gondol, Bali Tahun 2016. Larva dipelihara pada tiga buah bak semen ukuran $10 \mathrm{~m}^{3}$ yang diisi telur dengan kepadatan 50.000 butir/bak, dipelihara hingga juvenil umur 40 hari (D40). Pemeliharaan larva diulang tiga kali dengan waktu yang berbeda, yaitu siklus 1: Januari-Maret; siklus 2 : Mei-Juli dan siklus 3 : September-Nopember. Pengamatan perkembangan dan tingkah laku larva dilakukan pada setiap siklus yang dibagi menjadi 4 kelompok umur, yakni: 1) D1 sampai D10; 2). D11 sampai D20; 3). D21 sampai D30; dan 4). D31 sampai D40. Hasil menunjukkan larva ikan kerapu cantik mulai buka mulut dan makan pada D3, aktif berenang setelah tumbuh sirip punggung dan dada yaitu D4, sirip terus berkembang menjadi duri memanjang. D7 kondisi larva terlihat padat dilakukan penjarangan. Duri punggung dan dada mulai memendek, berubah menjadi sirip mulai D30, selanjutnya menjadi juvenil dilakukan grading untuk menekan kanibalisme, D40 dengan ukuran panjang total sekitar $3 \mathrm{~cm}$ larva ikan kerapu cantik seluruhnya menjadi juvenil. Perkembangan dan tingkah laku larva ikan kerapu cantik berpengaruh terhadap hasil produksinya.
\end{abstract}

Kata kunci: kerapu cantik, mendukung, pengamatan, perkembangan, produksi, tingkah laku 


\section{PENDAHULUAN}

Ikan kerapu adalah salah satu komoditas perikanan yang mempunyai nilai ekonomis yang tinggi, mempunyai harga yang mahal di tingkat pembudidaya. Jenisjenis ikan kerapu yang mempunyai harga yang mahal dipasaran antara lain genus: Epinephelus, Cromileptes dan Plectropomus (Rimmer et al., 2004). Pasar ekspor ikan kerapu dalam bentuk hidup terutama untuk pasar Asia seperti Hong Kong, Taiwan, Cina, Malaysia dan Singapuraa (Johnson and Yeeting, 2006).

Mengingat harga ikan kerapu yang tinggi dan hasil tangkapan dari alam yang terus menurun, maka budidaya ikan kerapu harus digalakkan dan saat ini telah berkembang dengan pesat. Seiring dengan perkembangan teknologi pembenihan, beberapa jenis benih ikan kerapu sudah dipasok dari hasil pembenihan secara kontinu sesuai permintaan. Produksi benih-benih ikan kerapu selain untuk mencukupi kebutuhan budidaya laut di Indonesia juga dikirim ke luar negeri diantaranya Singapuraa, Malaysia, Vietnam, Thailand, Taiwan, Hong Kong dan China (Heerin, 2002; Ismi, 2010).

Pembenihan ikan kerapu sudah berkembang, menjadi usaha masyarakat yang meguntungkan dan dapat menyerap banyak tenaga kerja (Siar et al., 2002). Salah satu benih yang banyak diminati adalah ikan kerapu cantik, yaitu hibrida antara betina kerapu macan (Epinephelus fuscoguttatus) dan jantan kerapu batik (Epinephelus microdon). Ikan kerapu batik pertumbuhannya lambat dan tahan terhadap penyakit, sampai saat ini masih susah untuk dibenihkan sehingga kelangsugan hidup masih rendah $(<5 \%)$, tetapi untuk konsumsi banyak diminati karena mempunyai rasa yang enak (Giri, 2001), sedangkan ikan kerapu macan mempunyai pertumbuhan yang lebih cepat dan pembenihannya mudah lakukan.
Ikan kerapu hibrida cantik mempunyai pertumbuhan yang cepat seperti ikan kerapu macan dan tahan terhadap penyakit seperti kerapu batik (Ismi et al., 2013). Tingkat kelangsungan hidup untuk benih ikan kerapu cantik dimasyarakat bisa mencapai di atas $10 \%$, namun hingga saat ini masih fluktuatif (Ismi, 2014), karena itu perlu adanya langkah-langkah untuk perbaikan cara pemeliharaan, sehingga bisa diperoleh hasil yang kontinu dan lebih baik, untuk dapat memperbaiki hasil produksi pada pembenihan, maka pada penelitian ini dicoba untuk mengamati tingkah laku larva sesuai dengan perkembangannya agar bisa diambil langkah-langkah untuk perbaikan pada produksi benih ikan kerapu cantik.

\section{METODE PENELITIAN}

Penelitian ini dilakukan di Balai Besar Riset Budidaya Laut dan Penyuluhan Perikanan Gondol, Bali pada Tahun 2016. Pemeliharaan larva dilakukan secara massal pada tiga buah bak semen ukuran $10 \mathrm{~m}^{3}$ yang diisi air laut 7-8 $\mathrm{m}^{3}$, telur kerapu hibrida cantik dengan perhitungan telur dengan cara sampling ditebar dengan kepadatan 50.000 butir/bak. Pengamatan tingkah laku larva pemeliharaan diulang tiga kali dengan waktu yang berbeda, yaitu siklus 1: Januari-Maret; siklus 2 : Mei-Juli dan siklus 3 : SeptemberNovember.

Setiap siklus pengamatan terhadap perkembangan dan tingkah laku larva ikan kerapu cantik yang dibagi menjadi 4 kelompok umur, yakni: 1) D1 sampai D10; 2). D11 sampai D20; 3). D21 sampai D30; dan D31 sampai D40. Larva ikan kerapu cantik dipelihara hingga mencapai juvenil yaitu hingga pengamatan 40 hari. Manajemen pembenihan mengikuti aturan Cara Pembenihan Ikan yang baik (CPIB) dan tahapan pemeliharaan larva mengikuti panduan yang disajikan pada Tabel 1 (Sugama et al., 2001; 2012). 
Tabel 1. Tahapan pemberian minyak, pakan dan pergantian air pada pemeliharaan larva ikan kerapu cantik.

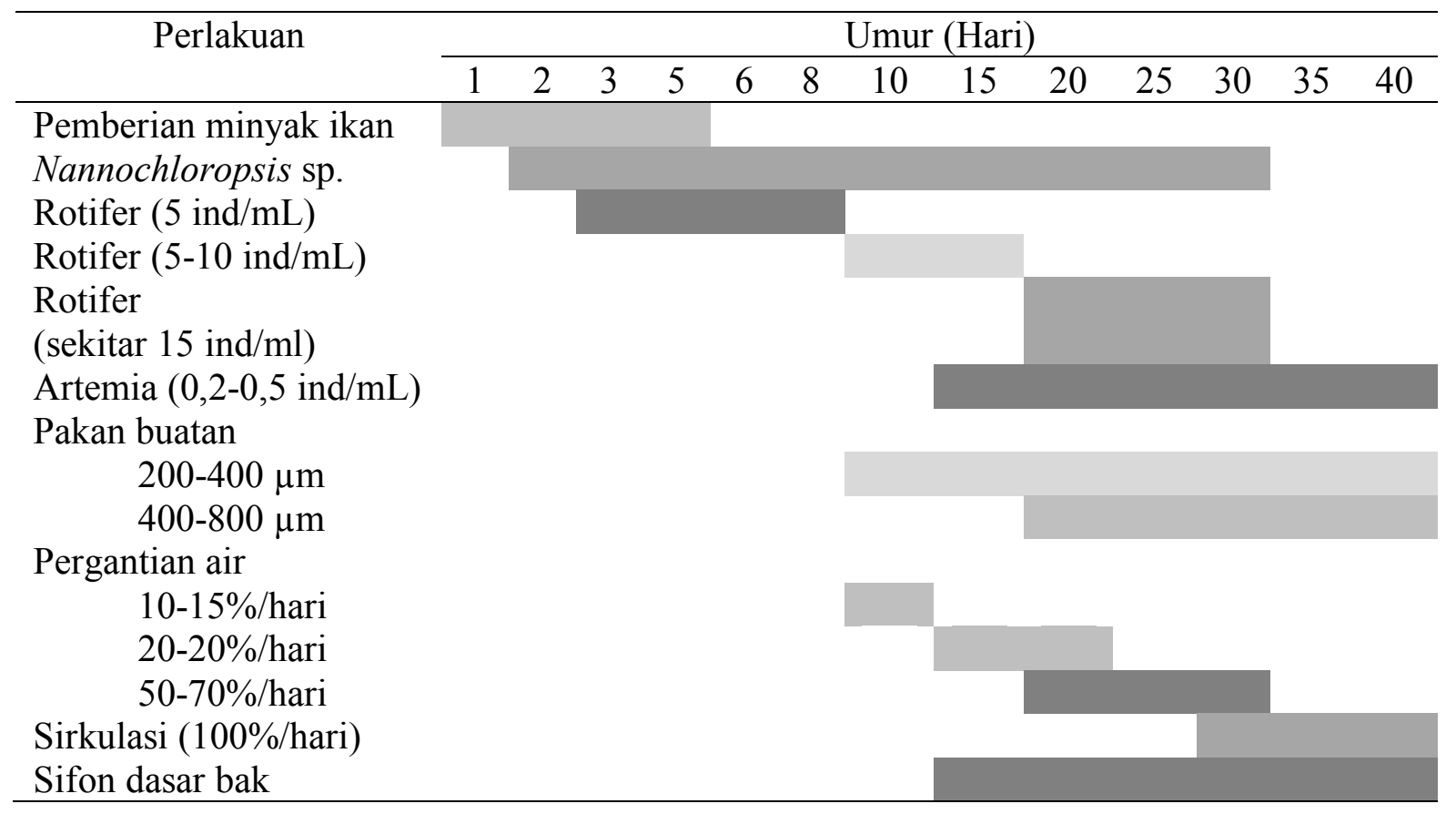

\subsection{Parameter Pendukung}

Tingkat penetasan larva dihitung dengan cara sampling pada pagi hari setelah telur menetas (larva umur D1). Air pemeliharaan diambil dengan mencelupkan pipa PVC (diameter pipa 1,5 inci dan panjang $1,5 \mathrm{~m}$ ) tegak lurus ke dalam bak di empat tempat yang berbeda. Volume air dan jumlah larva yang terambil dihitung, selanjutnya jumlah larva dalam bak dapat dihitung dengan konversi jumlah larva/satuan volume air sampel dikalikan volume air pemeliharaan.

Sebanyak 20 ekor larva diukur panjang totalnya, volume kuning telur (yolk sac) dan butir minyak (oil globule) pada larva yang baru menetas, pengukuran dengan menggunakan rumus (Bagarinao, 1986 dalam Villamizar et al., 2009).

SAI dihitung dengan cara memasukkan larva yang baru menetas 100 ekor ke dalam gelas beaker $1.000 \mathrm{~mL}$ tanpa diberi makan kemudian SAI ditentukan dengan cara menghitung jumlah larva yang hidup setiap hari hingga larva yang hidup tidak kurang dari $20 \%$ kemudian membaginya dengan jumlah larva awal penebaran (Hutapea et al., 2017).

Pertumbuhan diukur panjang totalnya dengan cara mengambil sampel 20 ekor setiap lima hari sekali. Kelangsungan hidup benih dihitung pada akhir penelitian dengan cara menghitung total benih yang didapat. Kualitas air : suhu dan oksigen terlarut (DO) diukur dengan YSI Pro 20, $\mathrm{pH}$ diukur dengan HANNA Hi 98191, salinitas diukur dengan refraktometer, diukur setiap pagi hari jam 10.00 Wita. Data ditampilkan dalam bentuk gambar dan tabel selanjutnya dianalisis secara deskriptif.

\section{HASIL DAN PEMBAHASAN}

\subsection{Perkembangan dan Tingkah Laku Larva Ikan Kerapu Cantik D1 sampai D10}

Pengamatan larva ikan kerapu cantik dari ke tiga siklus produksi mempunyai hasil yang sama yaitu setelah telur menetas hari pertama (D1) menjadi larva berwarna transparan dengan ukuran panjang total 2,59 $\pm 0,12 \mathrm{~mm}$. Larva melayang-layang 
menyebar ke semua kolom air dalam tangki pemeliharaan dengan posisi kepala menghadap ke bawah sekitar $45^{\circ}$ dari posisi ekor. Larva setelah menetas mempunyai kuning telur (KT) dengan volume sekitar 0,0172 \pm $0,00019 \mathrm{~mm}^{3}$ dan butir minyak (BT) volume $0,0032 \pm 0,00012 \mathrm{~mm}^{3}$ (Gambar 1A).

Larva pada umur dua hari (D2) (Gambar 1B.) posisi kepala ke bawah sekitar $90^{\circ}$ dari posisi ekor, larva banyak pada kolom tengah air hingga ke bawah karena itu pada larva tidak banyak kelihatan. Kuning telur sudah terserap dan mengecil tinggal tersisa sekitar $10 \%$ sedangkan butir minyak masih tersisa sekitar 30\% (Gambar 1B.), menurut Asih dan Ismi (2011) pada larva D2 kuning telur sudah banyak terserap sehingga hanya sisa $11,97 \%$, sedangkan butir minyak masih tersisa 54,83\% (Gambar 1A dan 1B).

Umur tiga hari (D3), kuning telur sudah habis terserap, sedangkan butir minyak masih tersisa sedikit. Menurut Ismi dan Asih (2011) kondisi ini sama pada larva ikan kerapu macan, sedangkan pada larva ikan kerapu batik kuning telur terserap habis lebih dari umur tiga hari tepatnya 85 jam dan butir minyak 95 jam setelah menetas (Slamet dan Tridjoko, 1997). Bersamaan dengan babisnya kuning telur mulut sudah membuka (tanda panah Gambar 1C) dengan bukaan mulut $127,16 \pm 0,019 \mu \mathrm{m}$ dan larva mulai memangsa makanan dari luar, anus mulai terbuka dan usus mulai berfungsi mencerna makanan terlihat mulai ada rotifer di dalam perut. Larva ikan sturgeon mulai umur tiga hari di

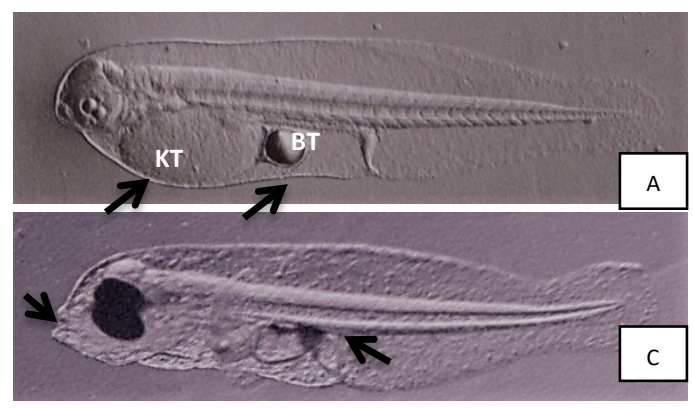

sekitar perut telah berpigmen berupa titiktitik hitam (melanophore), mata telah berwarna hitam dan lembaran yang nantinya menjadi sirip dada mulai tumbuh, aktif berenang dan mencari makanan (Wilga and Lauder, 1999).

Umur empat hari (D4) (Gambar 1D.) sirip dada dan punggung mulai tumbuh (tanda panah) sampai enam hari morfologi tidak banyak perubahan, melanophore bertambah di perut hinggga ekor, larva sudah aktif mencari mangsa, terlihat dari semakin banyak rotifer dalam perut larva. Jumlah rotifer dalam perut larva ikan kerapu macan menunjukan kecenderungan peningkatan seiring dengan meningkatnya umur larva, terlihat pada umur 3 dan 5 hari terdapat masing-masing 6,30 $\pm 0,02$ dan $12,00 \pm 8,66$ individu rotifer, dan terus bertambah hingga $74,31 \pm 26,44$ dan $96,90 \pm 51,27$ individu pada umur 17 dan 20 hari (Melianawati dan Pratiwi, 2011).

D7 sirip punggung dan dada mulai berubah menjadi duri, selanjutnya D8 duri semakin nampak seperti duri hitam di ujungnya (Gambar 2A). Pada D7 larva sudah mulai bergerombol di sudut dan tepi tangki pemeliharaan, jika kondisi larva padat maka harus mulai dilakukan penjarangan. Larva terus bertambah banyak bergerombol dengan posisi vertikal dari dasar hingga permukaan, dengan bertambahnya umur duri punggung dan dada semakin panjang dan gerakan larva semakin lincah sehingga setelah D10 larva sudah susah untuk ditangkap (Gambar 2B).

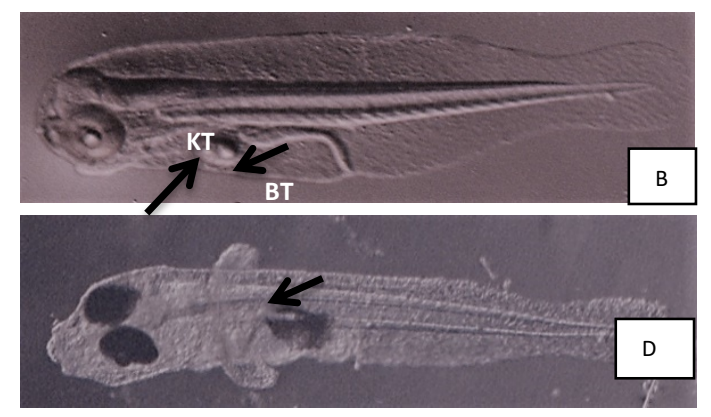

Gambar 1. Perkembangan larva ikan kerapu cantik A. larva umur 1 hari, B. larva umur 2 hari, C. larva umur 3 hari dan D. larva umur 4 hari. (Semua gambar diamati dengan mikroskop pembesaran $4 \mathrm{x}$ ). 

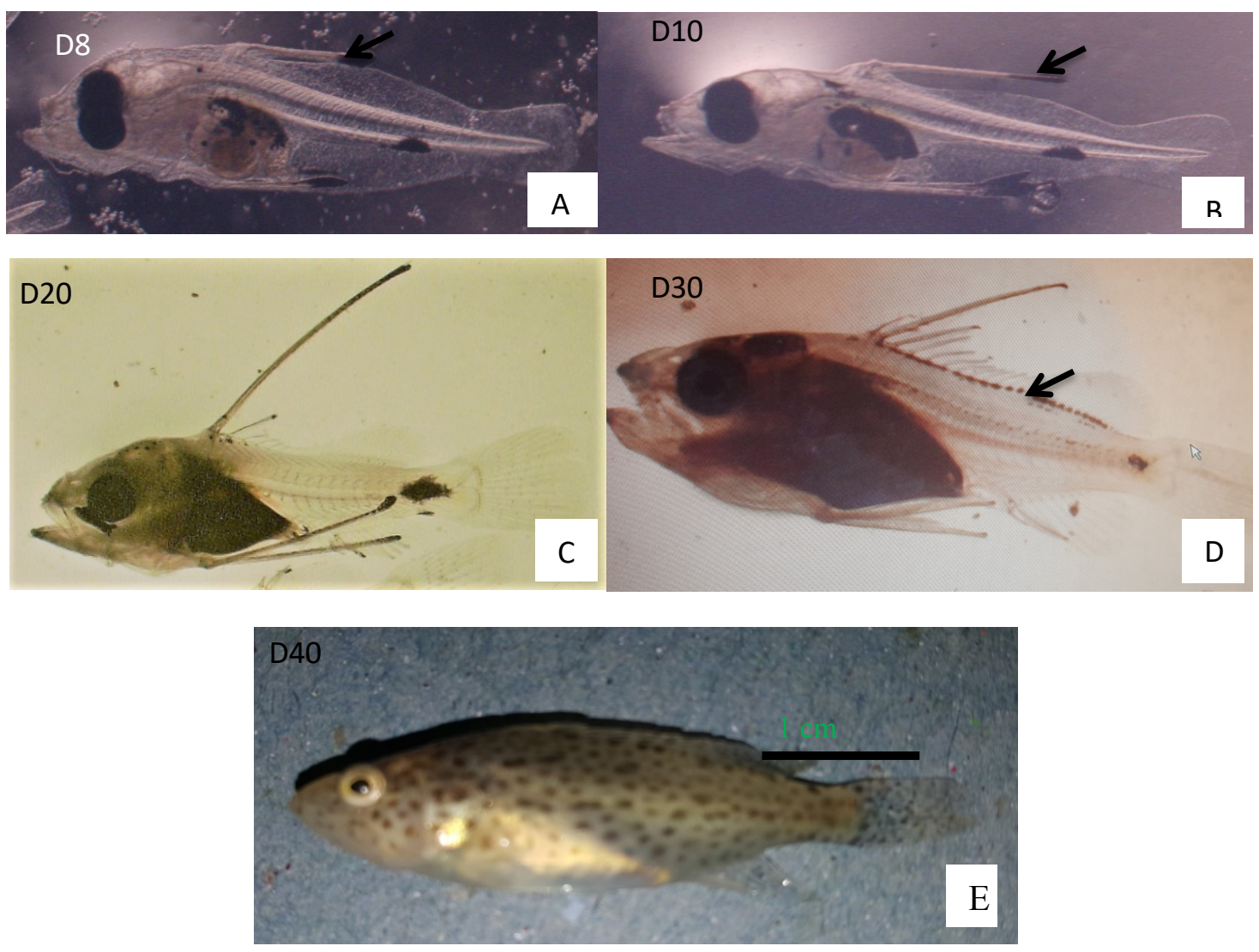

Gambar 2. Perkembangan larva ikan kerapu cantik A. larva umur 8 hari, B. larva umur 10 hari. (Gambar A dan B diamati dengan mikroskop pembesaran $3 \mathrm{x}$ ), C. larva umur 20 hari, D. larva umur 30 hari, dan E. juvenile umur 40 hari. (Gambar C dan D diamati dengan mikroskop pembesaran $0,8 \mathrm{x}$ ).

\subsection{Perkembangan dan Tingkah Laku Larva Ikan Kerapu Cantik D11 sampai D20}

Larva pada umur 11 sampai 20 hari (Gambar 2C.) performen larva tidak berubah, pada duri sirip pungung dan dada terus memanjang dan gerakan semakin aktif, usus terus berkembang, jumlah rotifer dalam perut semakin banyak larva telah aktif makan pakan buatan sehingga perut kelihatan besar. Pakan buatan mulai diberikan pada umur 8 pemberian dilakukan sedikit demi sedikit, untuk melatih larva agar mau dan terbiasa dengan pakan buatan karena larva hanya memakan pakan yang melayang. Jumlah pakan buatan yang dimanfaatkan larva masih terbatas maka pemberian pakan buatan pada umur tersebut harus dibatasi dengan pemberian pakan alami yang seimbang dan cukup hal ini berhubungan dengan kemampuan pada larva umur tersebut menghidrolisa pakan buatan masih rendah (Melianawati dan Pratiwi, 2011). Ketidak cukupan pemberian pakan alami, maka larva akan banyak memakan pakan buatan yang diberikan, dengan banyaknya pakan buatan yang termakan larva, apabila larva tidak bisa mencerna dengan sempurna maka akan terjadi kematian (Cohu and Infante, 2001).

\subsection{Perkembangan dan Tingkah Laku Larva Ikan Kerapu Cantik D21 sampai D30}

Umur 21 hingga 30 hari (Gambar 2D) larva sudah aktif makan pakan buatan, copepod, artemia, badan larva ikan kerapu cantik sudah mulai berwarna terutama bagian kepala mulai gelap duri punggung dan dada 
mulai menebal dan duri mulai memendek dan dari punggung sampai ekor atas dan bawah mulai tumbuh calon sirip. Larva sudah menyerupai ikan meskipun duri punggung dan dada masih nampak dan sepenuhnya belum berupa sirip.

\subsection{Perkembangan dan Tingkah Laku Larva Ikan Kerapu Cantik D31 sampai D40}

Setelah umur 30 hari beberapa larva sudah mengalami metamorfosa menjadi bentuk ikan kecil/juvenil, setelah umur 35 hari telah banyak yang berbentuk juvenil ditandai dengan sudah tidak adanya duri pada punggung dan dada, pada umur 40 hari larva ikan kerapu cantik sudah menjadi juvenil sempurna (Gambar 2E). Mulai berubah menjadi juvenil sifat kanibal mulai muncul, ukuran yang lebih besar menyerang yang lebih kecil. Saat ini ikan harus mulai grading (Ismi et al., 2012) dikelompokkan sesuai ukuran untuk menekan kanibalisme, hasil pengelompokan ukuran terdiri dari grade A $(3,7 \pm 0,351 \mathrm{~cm}) ; \mathrm{B}(2,6 \pm 0,50 \mathrm{~cm})$ dan $\mathrm{C}$ $(2,0 \pm 0,57 \mathrm{~cm})$.

Hasil pengamatan untuk parameter pendukung pada pemeliharaan larva ikan kerapu cantik, untuk pengamatan perkembangan dan tingkah laku dari hasil ke tiga siklus mempunyai daya tetas telur, ketahanan hidup larva dan nilai indeks ketahanan hidup larva (SAI) dan juga kelangsungan hidup ditampilkan Tabel 2.

Nampaknya daya tetas telur memengaruhi kualitas larva ikan kerapu cantik, terbukti pada siklus pertama telur mempunyai daya tetas tinggi menghasilkan ketahanan larva yang tinggi sampai enam hari dengan SAI dan kelangsungan hidup paling tinggi dibandingkan siklus yang lain. Hal ini sesuai dengan pernyataan Matsuo et al. (2006) bahwa larva dengan nilai SAI yang tinggi akan menghasilkan kelangsungan hidup larva yang lebih tinggi dibandingkan dengan larva yang mempunyai SAI rendah.

SAI (Survival Activity Index) atau nilai indeks ketahanan hidup larva yakni kemampuan hidup larva dengan mengandalkan cadangan energi bawaan yaitu kuning telur dan butir minyak. Tetapi menurut Wang el al. (2013) nilai SAI tidak hanya berhubungan dengan penyimpanan cadangan energi atau nutrien dalam tubuh larva tetapi dipengaruhi oleh lingkungan pemeliharaan seperti suhu dan salinitas. Terbukti dari hasil penelitian ini dengan kisaran yang lebih tiggi yaitu pada siklus 1 dengan kisaran suhu 29,1$30,6^{\circ} \mathrm{C}$ ) menghasilkan SAI lebih tinggi disusul oleh siklus $3\left(28,4-32,5^{\circ} \mathrm{C}\right)$ dan SAI paling rendah adalah siklus 2 dengan suhu $\left(26,2-30-0^{\circ} \mathrm{C}\right)$.

Hasil dari penelitian ini nampaknya dengan mengetahui perkembangan dan tingkah laku larva yang juga dapat membantu meningkatkan produksi yang disajikan pada tabel 2, dibandingkan produksi sebelumnya yang rata-rata hanya menghasilkan pada kelangsungan hidup untuk kerapu macan $8,3 \%$, kerapu cantang $11,6 \%$ dan kerapu cantik 11,4\% (Ismi, 2014).

Tabel 2. Hasil pengamatan daya tetas telur, ketahanan hidup larva dan nilai indeks ketahanan hidup larva (SAI) dari tiga siklus ulangan produksi.

\begin{tabular}{lccc}
\hline \multirow{2}{*}{ Parameter } & I & II & III \\
\cline { 2 - 4 } & Januari - Maret & Mei - Juli & September - November \\
\hline Daya tetas telur (\%) & 90,2 & 76,5 & 81,3 \\
$\begin{array}{l}\text { Ketahanan hidup larva (hari) } \\
\begin{array}{l}\text { Nilai indeks ketahanan } \\
\text { hidup larva (SAI) }\end{array}\end{array}$ & 6,0 & 4,0 & 5,0 \\
$\begin{array}{l}\text { Kelangsungan hidup benih } \\
(\%)\end{array}$ & 3,01 & 2,05 & 2,64 \\
\hline
\end{tabular}




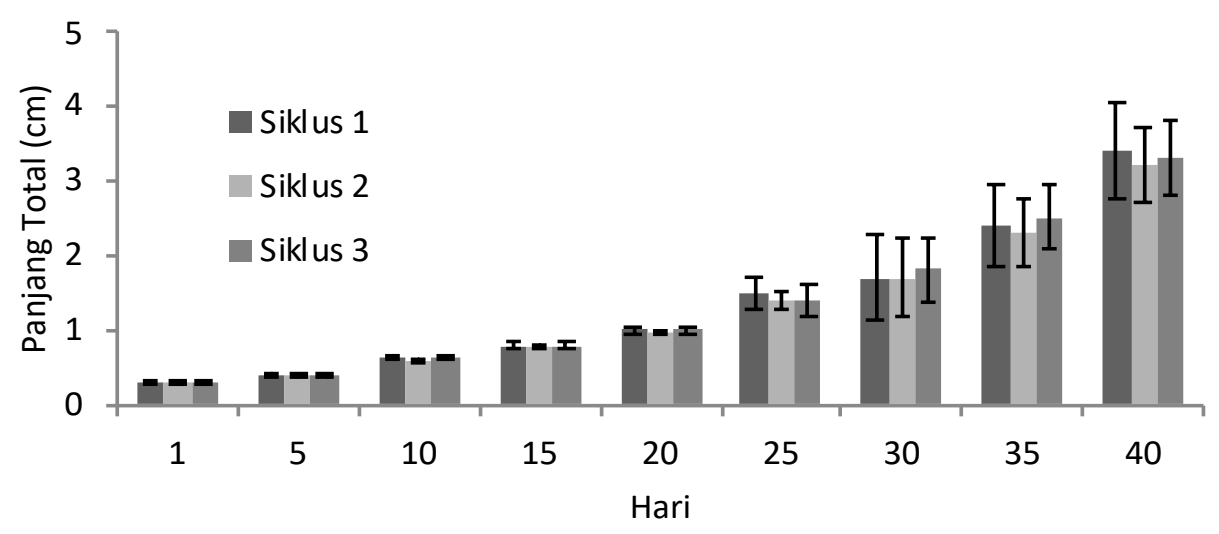

Gambar 3. Panjang total larva ikan kerapu cantik pada siklus 1 (Januari-Maret); siklus 2 (MeiJuli) dan siklus 3 (September-November).

Tabel 3. Kisaran kualitas air ke tiga siklus produksi masal benih ikan kerapu cantik.

\begin{tabular}{lccc}
\hline \multirow{2}{*}{ Parameter } & \multicolumn{3}{c}{ Siklus } \\
\cline { 2 - 4 } & 1. (Januari-Maret) & 2. (Mei-Juli ) & 3. (September-November) \\
\hline Suhu $\left({ }^{\circ} \mathrm{C}\right)$ & $29,1-30,6$ & $26,6-30,0$ & $28,4-32,5$ \\
Salinitas & $33,0-34,0$ & $33,0-34,0$ & $33,0-34,0$ \\
(ppt) & $5,2-6,2$ & $5,1-6,3$ & $5,2-6,3$ \\
DO $(\mathrm{ppm})$ & $8,2-8,3$ & $8,1-8,2$ & $8,2-8,3$ \\
pH & &
\end{tabular}

Pertumbuhan yang diukur dari panjang total (TL), setiap 5 hari sekali dari ke tiga siklus tidak menujukkan perbedaan pada akhir penelitian umur 40 hari ikan sudah menjadi juvenil semua dengan panjang rata-rata 3,2 -3,4 cm, seperti nampak pada (Gambar 3).

Kisaran kualitas air pada tiga siklus dapat dilihat pada Tabel 3 nampaknya parameter yang berubah pada masing-masing siklus adalah suhu. Siklus pertama dengan kisaran suhu $29,1^{\circ} \mathrm{C}-30,6^{\circ} \mathrm{C}$ fluktuasi suhu air maksimal-minimal sebesar $1,5^{\circ} \mathrm{C}$ menghasilkan daya tetas telur, 'SAI dan kelangsungan hidup yang lebih baik dari siklus yang lainnya (Tabel 2.). Aslianti et al. (2008), menyatakan bahwa pada pemeliharaan larva kerapu suhu air pemeliharaan larva berkisar berkisar $29^{\circ} \mathrm{C}-30^{\circ} \mathrm{C}$ dengan kisaran perbedaan suhu maksimum-minimum sebesar $1{ }^{\circ} \mathrm{C}-1,5^{\circ} \mathrm{C}$. membuat larva tumbuh normal dan kelangsungan hidup lebih tinggi.
Menurut Akatsu (2006) dan Swastika et al. (2007) suhu rendah adalah salah satu faktor pembatas untuk pertumbuhan larva, fluktuasi suhu yang besar menyebabkan respons makan berkurang yang mempengaruhi pertumbuhan. Turunnya suhu $25^{\circ} \mathrm{C}-27^{\circ} \mathrm{C}$ pada pemeliharaan kerapu menyebabkan berkurangnya daya tetas telur (Suwirya et al., 2006). Hasil pengamatan walaupun suhu berpengaruh terhadap daya tetas telur, SAI dan kelangsungan hidup namun perkembangan dan tingkah laku larva ikan kerapu cantik dari ke tiga siklus adalah sama.

\section{KESIMPULAN}

Larva ikan kerapu cantik mengalami beberapa tahap perubahan bentuk dari menetas, buka mulut, tumbuh sirip yang selanjutnya memanjang menjadi duri dan memendek perlahan berubah menjadi sirip, hingga menjadi juvenil sempurna seluruhnya 
pada umur 40 hari. Perkembangan dan tingkah laku larva ikan kerapu cantik tidak berbeda walaupun diproduksi pada waktu yang berbeda, sehingga berpengaruh adalah hasil produksinya yang dipengaruhi oleh faktor lingkungan terutama suhu, dengan mengetahui perkembangan dan tingkah laku larva sangat membantu dalam proses pemeliharaan sehingga dapat meningkatkan hasil produksi.

\section{UCAPAN TERIMA KASIH}

Terima kasih kepada teknisi larva Bapak Putu Suarjana, Bapak I Gusti Putu Oka Suarjana dan Bapak Kariyanto. Teknisi pakan alami Bapak I. Nyoman Restiada, Bapak Feri Priatna, Bapak Kadek Ardika dan Bapak Muhdiat, atas peran sertanya membantu hingga penelitian ini selesai.

\section{DAFTAR PUSTAKA}

Akatsu, S. 2006. Grouper culture. Paper for training course on Sustainable Mariculture Technology-2 by Japan International Cooperation Agency (JICA). Yokohama Training Center, Oct. $4^{\text {th }} 2006.7 \mathrm{p}$.

Aslianti, T., K. Suwirya, dan Asmanik. 2008.Teknologi pemeliharaan larva kerapu sunu (Plectropomus leopardus) secara massal. J. Ris. Akuakultur, 3(1):1-11.

Asih, Y.N. dan S. Ismi. 2011. Penggunaan energi endogen pada larva kerapu hybrid cantik (kerapu macan, Epinephelus fuscoguttatus $\mathrm{x}$ kerapu batik, Epinephelus mikrodon). Dalam Sudradjat et al., (eds.). Prosiding Forum Inovasi Teknologi Akuakultur Jilid 1, Pusat Penelitian dan Pengembangan Perikanan Budidaya. Sanur-Bali, 19-21 Juli 2011. Hlm.:875-878.

Cohu, C. and J.Z. Infante. 2001. Sustitution of live food by formulated diets in marine fish larvae. Aquaculture, 22:161-180.

Heerin, S.V. 2002. Technology transferbackyard hatcheries bring jobs, growth to Bali. Global Aquaculture Advocate, December 2002. 90-92 pp.

Hutapea, J.H., A. Setiadi, Gunawan dan I.G.N. Permana. 2017. Performa pemijahan ikan tuna sirip kuning, Thunnus albacares di karamba jaring apung. J. Riset Akuakultur, 12(1):4956.

Giri, N.A. 2001. Pembenihan ikan kerapu batik (Epinephelus microdon) sebagai upaya penyediaan benih untuk pengembagan budidaya laut. Warta Penelitian Perikanan Indonesia. $32 \mathrm{p}$.

Ismi, S. 2010. Grouper hatchery business empowerment for coastal community. Dalam: Sudaryono et al. (eds.). Proceeding International Conference of Aquaculture Indonesia (ICAI) and International Conference on Shrimp Aquaculture (ICOSA) 2010. Masyarakat Akuakultur Indonesia, Universitas Diponegoro Semarang. Hlm.:1147-1150.

Ismi, S. dan Y.N. Asih. 2011. Perkembangan telur dan tingkah laku larva kerapu hybrid cantang. Dalam Sudradjat et al., (eds.). Prosiding Forum Inovasi Teknologi Akuakultur. Bali19-21 Juli 2011. Hlm.:9-12.

Ismi, S. 2014. Aplikasi teknologi pembenihan kerapu untuk mendukung pengembangan budidaya laut. J. Ilmu dan Teknologi Kelautan Tropis, 6(1):109-119.

Ismi, S., T. Sutarmat, N.A. Giri, M.A. Rimmer, R.M.J. Knuckey, A.C. Berding, and K. Sugama. 2012. Nursery management of grouper: a best-practice manual. Australian Centre for International Agricultural Research (ACIAR) 2012. 44 p.

Ismi, S., Y.N. Asih, dan D. Kusumawati. 2013. Peningkatan produksi dan kualitas benih ikan kerapu melalui 
program hibridisasi. J. Ilmu dan Teknologi Kelautan Tropis, 5(2): 333342.

Ismi, S. 2014. Aplikasi teknologi pembenihan kerapu untuk mendukung pengembangan budidaya laut. J. Ilmu dan Teknologi Kelautan Tropis, 6(1):109-119.

Matsuo, Y., Y. Kasahara, A. Hagiwara, Y. Sakukara, and T. Arakawa. 2006. Evaluation of larval quality of viviparous scorpion fish, Sabastiscus mormoratus. Fisheries Science, 72(5):948-954.

Melianawati, R. dan R. Pratiwi. 2011. Pola aktivitas pencernaan larva ikan kerapu macan (Epinephelus fuscoguttatus Forsskal, 1775). J. Ris. Akuakultur, 6(1):51-63.

Johnston, B. and B. Yeeting. 2006. Economics and marketing of the live reef fish trade in Asia-Pacific. ACIAR Working paper No. 60. Australian Centre for International Agricultural Research: Canberra. 30 p.

Rimmer, M.A, Mc Bride, and K.C. William. 2004. Advances in grouper aquaculture. ACIAR Monograph No. 110. Australian Centre for International Agricultural Research. 24 p.

Suwirya, K., A. Prijono, A. Hanafi, R. Andamari, R. Melianawati, M. Marzuqi, K. Sugama, dan N.A. Giri. 2006. Pedoman teknis pembenihan Ikan Kerapu Sunu (Plectropomus leopardus). Pusat Riset Perikanan Budidaya. Badan Riset Kelautan dan Perikanan. $18 \mathrm{hlm}$.

Siar, S.V., W.L. Johnston, and S.Y. Sim. 2002. Study on economics and socio-economics of small-scale marine fish hatcheries and nurseries, with special reference to grouper systems in Bali, Indonesia. Report Prepared under Asia-Pacific Economic Cooperation (APEC) Project FWG 01/2001:
'Collaborative APEC Grouper

Research and Development

Network'. Asia-Pacific Marine Finfish Aquaculture Network Publication 2/2002. Network of Aquaculture Centres in AsiaPacific:Bangkok, Thailand. $21 \mathrm{p}$.

Slamet, B., Tridjoko, A. Prijono, T. Setiadarma, dan K. Sugama. 1996. Penyerapan nutrisi endogen, tabiat makan dan perkembangan morfologi larva kerapu bebek (Cromileptes altevelis). J. Penelitian Perikanan Indonesia, 2(2):13-21.

Slamet, B. dan Tridjoko. 1997. Pengamatan pemijahan alami, perkembangan embrio dan larva ikan kerapu batik (Epinephelus microdon) dalam bak terkontrol. J. Penelitian Perikanan Indonesia, 3(4):40-50.

Sugama, K., Tridjoko, B. Slamet, S. Ismi, E. Setiadi, dan S. Kawahara. 2001. Petunjuk teknis produksi benih ikan kerapu bebek, Cromileptes altivelis. Balai Riset Budidaya Laut Gondol, Pusat Riset dan Pengembangan Eksploirasi laut dan Perikanan Departemen Kelautan dan Perikanan dan Japan International Cooperation Agency. $40 \mathrm{p}$.

Sugama, K., M.A. Rimmer, S. Ismi, I. Koesharyani, K. Suwirya, N.A. Giri, and V.R. Alava. 2012. Hatchery management of tiger grouper (Epinephelus fuscoguttatus): a bestpractice manual. Australian Centre for International Agricultural Research (ACIAR) 2012. 66 p.

Suastika, M., P.T. Imanto, dan A. Prijono. 2007. Studi awal pada keragaan pemijahan induk kerapu sunu (Plectropomus sp.) perkembangan embrio dan penetasan. Buku Pengembangan Teknologi Budidaya Perikanan. Balai Besar Riset Perikanan Budidaya Laut. Badan Riset Kelautan dan Perikanan. 420$426 \mathrm{pp}$. 
Villamizar, N., A. Garcia-Alcazar, and F.J. Sanchez-Fazquez. 2009. Effect of light spectrum and photoperiod on the growth, development and survival of European sea bass (Dicentrarchus labrax) larvae. Aquaculture, 292:8086.

Wang, Y., L.Li., G. Cui. and W. Lu. 2013. Ontogenis from embryo to juvenile and salinity tolerance of Japanese devil stinger Inimicus japonicas during early stage. SpringerPlus, 2 : 289.http://www.springerplus.com.content/2/1 /289. (Retrieved on 28 March 2018).

Wilga, C.D. and G.V. Lauder. 1999. Locomotion in sturgeon: function of the pectoral fins. The J. Experimental Biology, 202:413-432.
Diterima : 30 Mei 2018
Direview : :05 Juni 2018
Disetujui : :05 Juli 2018 